\title{
Challenges Faced in Inter-Organizational Collaboration Process. A Case Study of Region Skåne
}

\author{
Namonda Kwibisa ${ }^{1} \&$ Safaa Majzoub ${ }^{1}$ \\ ${ }^{1}$ Malmö University, Malmö, Sweden \\ Correspondence: Safaa Majzoub, Malmö University, Malmö, Sweden. E-mail: safaa.majzoube@hotmail.com
}

Received: June 23, 2018

Accepted: August 21, $2018 \quad$ Online Published: September 18, 2018

doi:10.5539/jsd.v11n5p34

URL: https://doi.org/10.5539/jsd.v11n5p34

\begin{abstract}
The increase in the complexity of social and societal problems that even a large actor cannot solve alone has caused pressure on many sectors, organizations and entities making the need for collaboration to be more urgent. This is because collaboration enables merging financial resources, human resources and expertise needed to tackle complex problems. However, the increased failure of collaborations requests greater consideration and investigation of the challenges in collaboration. The purpose of this study is to investigate the challenges in inter-organizational collaboration at management and employee level with a focus on the Thomson and Perry (2006), model of collaboration. To fulfil this purpose, inter-organizational collaboration towards open Skåne 2030 strategy was used as a case study. The empirical data showed that there are challenges in both the management and employee level in inter-organizational collaboration. Further, the study also found that political influence is a major challenge in inter-organizational collaboration. The study makes a contribution with the adaption of the model of collaboration process. The model serves to enlighten collaborators that challenges in inter-organizational collaboration are inter-linked.
\end{abstract}

Keywords: inter-organizational collaboration, collaboration process, management level, employee level

\section{Introduction}

\subsection{Importance of Inter-Organizational Collaboration}

Collaboration is increasingly playing an important role in development driven by the need to jointly mobilize and connect assets and resources to achieve self-sufficiency and sustainable development (Torres-Rahman, Baxter \& Rivera; 2015). As the complexity of social and societal problems increases, that even a large actor cannot solve alone, the need for collaboration becomes more urgent. Building partnership models which are long lasting, scalable and transformative, and which create shared value is therefore key (Torres-Rahman, Baxter \& Rivera; 2015). The rapid transformation heralded by the fourth industrial revolution affects economic, social, environmental, cultural and political life more widely and thus, demanding new ways of working together (Mangoyana. et al, 2014). Already, traditional boundaries between the sectors have become blurred, with a less direct role for governments and wider governance role for business and civil society (Mangoyana. et al, 2014).

Inter-organizational collaboration is hence growing in significance due to continued social, economic and environmental problems coupled with a quest for competitive advantage and the urgent need to solve social and environmental problems faced in the world today (Moulaert et al., 2013). Collaboration presents significant opportunities for long-lasting, meaningful solutions through working with other organizations, sectors, and partners for additional knowledge of problems, resources or support in the implementation of solutions (Greer, 2017).

\subsection{Sustainability and Inter-Organizational Collaboration}

In the context of global instability and economic transformation, there are new opportunities and new responsibilities for each sector and, increasingly, a shared set of interests in achieving the kind of world envisaged in the UN's Sustainable Development Goals (SDG). Not least in SDG 17 which is about creating partnerships for the goals and SDG 11 aimed at creating sustainable cities and communities (United Nations Sustainable Development, 2018). In order to achieve a sustainable development, it is important that all levels of the society share responsibility and participate in finding sustainable solutions. This leads to creating an open society that welcomes pluralism, more people, and new ideas. As for this study which focuses on regional 
development, there is a need for a development strategy that is conducted openly, inclusively and with continual dialogue in order to achieve more sustainable growth and greater appeal. Furthermore, a regional collaborative strategy must encourage inhabitants, municipalities, authorities, colleges and universities, trade and industry, and the idea-based sector to collaborate in order to tackle social needs and create opportunities (Skane2030.se, 2018).

A decisive success of achieving sustainable regional development is dependent on a collaborative network that aims to solve the regional problems and conducts the collective actions needed for sustainable growth (Greer, 2017). According to Gray (1989), collaboration is a process through which different parties and stakeholders see a problem differently, can explore their differences and find ways to resolve the problems that can go beyond what they can think of as possible. But since collaboration for sustainable development is about collective actions that aim to achieve a shared goal, a member also has to engage in collective behavior such as working on a shared goal, spending time on verbal communication, and working on difficult situations. In order to achieve sustainable development in region Skåne, different organizations and stakeholders have therefore decided to collaborate towards open Skåne 2030 strategy which is the collaboration context used as a case for this study.

\subsection{Case Description}

\subsubsection{Region Skåne}

Skåne County is sometimes referred to as Scania County in English, is the southernmost county of Sweden. It borders the counties of Halland, Kronoberg and Blekinge. Skåne is used to be a Danish region but it became Swedish in 1658 although the Danish connection is still visible. Skåne county represents more than 174 nationalities and about 150 languages are spoken (Skane.se, 2018). Region Skåne is a self-governing administrative region, funded by taxes, which is governed by a Regional Council of 149 members who are directly elected by the inhabitants of Skåne. Region Skåne is responsible for healthcare and public transport, business development, culture, infrastructure, social planning and environmental and climate-related issues in Skåne. With 32,000 employees, Region Skåne is one of Sweden's biggest employers. The overarching vision for Region Skåne is "World class quality of life". Therefore, together with the municipalities in Skåne, institutes of higher education, organizations and trade and industry, Region Skåne operates on a broad front to create health, development and sustainable growth in Skåne (Skane.se, 2018)

Collaboration and sharing across boundaries are a prerequisite for the creation of a successful, sustainable region according to the vision of the region. Skåne's geographical location and proximity to Copenhagen has naturally led to intensive collaboration across the Öresund, and the labour markets in Skåne and on Zealand are becoming increasingly integrated. Region Skåne also has wide-ranging involvements with other regions, both near and far. There are partnerships in various areas with places including Hamburg and Schleswig-Holstein in Germany, Western Pomerania in Poland and the Guangdong region and the metropolis of Tianjin in China. In this case study we are focusing on the collaboration between sectors at the regional level (Skane.se, 2018)

\subsubsection{Strategy Formulation}

There are many challenges that region of Skåne faced which led to the creation of the open Skåne 2030 strategy. Among them, was growing population, residents were living longer, Skane's inhabitants were becoming healthier, many were not doing well, there was high international renown but associated with integration problems (Skane2030.se, 2018). Further, the level of education in Skåne was high, while too few qualified for secondary school, too few were in work, even if the demand for employees was great. Skane exhibited strong innovation but needed more viable and growing companies, it also had low productivity and taxable capacity compared to the rest of Sweden. Skåne had low growth and major environmental challenges. This indicates that Skane was both multifaceted and contradictory and these paradoxes reflected Skåne's position in 2014 (Skane2030.se, 2018).

Region Skåne under Swedish legislation on regional development responsibility was given a permanent mandate to coordinate regional development issues as a way of tackling these challenges including heading the work to draw up the regional development strategy (Skane2030.se, 2018). The regional development strategy; open Skåne 2030 was therefore developed in 2014 to formulate and create a broad joint approach to a common strategic objective for Skåne looking to the year 2030. The strategy was developed from a large number of analysis meeting, conducted over a period of two years (2012 to 2014). Also, based on Organization for Economic Co-operation and Development (OECD) 's review of Skane together with comprehensive material and published reports and statistics, a selection of facts is summarized in the focus of Skane 2030 strategy (Skane2030.se, 2018). The strategy presents five prioritized focus areas which are that by 2030, Skåne shall; offer optimism and quality of life, be a strong sustainable growth engine, benefit from urban structure, develop the welfare service of tomorrow and create a Skåne that is globally attractive (Skane2030.se, 2018). 


\subsubsection{Collaboration towards the Strategy}

Inter-organizational collaboration may not be the only or best process for every problem or issue, but it is an option when the problems being faced affect more than one sector, are complex, driven by multiple factors and cannot be resolved by one organization (Crosby and Bryson 2005). This is the case with open Skåne 2030 strategy which requires collaboration as it cannot be attained in one process with one given leader or organization hence calling for different actors from state to local level and across sectors while having continual dialogue into new knowledge in order to infuse new perspectives. Therefore, Skåne's inhabitants, municipalities, authorities, colleges and universities, trade and industry and the idea-based sector are collaborating and networking to achieve more sustainable growth and better appeal for Skåne looking to the year 2030 (Skane2030.se, 2018).

Collaboration between different actors was deemed necessary in order to implement the strategy and contribute to the creation of a context, a story for those who live in Skane (Skane2030.se, 2018). This because collaboration entails not so much compromising but rather complimenting and strengthening one another. Furthermore, this joint action strategy is reciprocal as in various ongoing processes operating in parallel, one or more actors identify an opportunity, take a joint stance and formulate a joint strategic objective to achieve (Skane2030.se, 2018). Based on this, jointly-processed strategic objectives, priorities, and standpoints are made to fulfill different opportunities and tackle different challenges, which results in different processes and actors being activated, which in turn results in initiatives and actions (Skane2030.se, 2018). So, Skane's development entails actors and processes moving around in this mutual interaction continually. These movements create new conditions and opportunities and thus new collaborations.

\subsection{Problem Statement}

Challenges in inter-organizational collaboration is a topic that scholars have studied worldwide because inter-organizational collaborations often do not function as expected as they encounter challenges which affect the attainment of desired results (Thomson \& Perry, 2006). Scholars have investigated the challenges in the collaboration process in general, but this study investigated challenges in the collaboration process in both management and employee level towards implementation of the regional strategy. Mattessich et al. (2001), believes that there is a need for mechanisms to involve both managers and participants from different levels of the organization if inter-organizational collaborations are to be successful. Studying challenges in inter-organizational collaboration at both management and employee level is therefore imperative.

\subsection{Purpose}

The purpose of this study was to investigate challenges in inter-organizational collaboration process at management and employee level with a focus on selected organizations that are collaborating towards the achievement of open Skåne 2030 strategy. To meet this purpose, the researchers investigated these challenges using Thomson \& Perry (2006), a model of collaboration which focuses on five dimensions (governance, administration, autonomy, mutuality, and norms).

\subsection{Research Question}

With a focus on the Thomson and Perry (2006), a model of collaboration, what are the challenges faced in the collaboration process at management and employee level.

\subsection{Limitations}

Although this research was carefully prepared, researchers still faced some limitations. Time was a limitation of this study as 6 weeks was not enough to conduct the study. Because of the time limitation, this research was only conducted only on a small size of participants. Therefore, to generalize the study for larger groups the study should have involved more interviews at different levels.

\subsection{Delimitations}

There are different phases of inter-organizational collaboration that have been highlighted in the literature. For this study, the Wood and Gray (1991), three phases of inter-organizational collaboration (preconditions-process-outcome) was used. The study was, however, was delimited to the process and excluded the other phases. Additionally, the study had its focus on collaboration towards the implementation of the 2030 open Skåne strategy which encompasses a vast diversity including Skåne's inhabitants, municipalities, authorities, colleges and universities, organizations, NGOs, trade and industry and the idea-based sector. The vast diversity of these collaborations made it necessary to delimit the focus to only inter-organizational collaboration and exclude other forms of collaborations. 


\section{Theoretical Framework}

\subsection{Three Phases of Collaboration}

As highlighted in section 1.8 (delimitations), the Wood and Gray (1991), three phases of collaboration was used in this study to provide understanding and insight of collaboration and also to structure the focus of the study. The model is comprised of three phases of collaboration namely; preconditions-process-outcome. Wood and Gray (1991), mapped different perspectives of collaboration in their literature review in order to come up with this model. Wood and Gray (1991), define the three phases of collaboration as follows; the conditions that motivate and encourage stakeholders to participate in collaborative activities are said to be the pre-conditions while structure for different ways how the collaborative activity practically is undertaken and upheld is said to be the process. Lastly, the desired outcome of the collaborative undertaking is said to be the outcomes. This study, therefore, adopted the definition of the process as defined by Wood and Gray (1991) and focused on studying challenges in the inter-organizational process. The diagram below shows these three phases of collaboration.

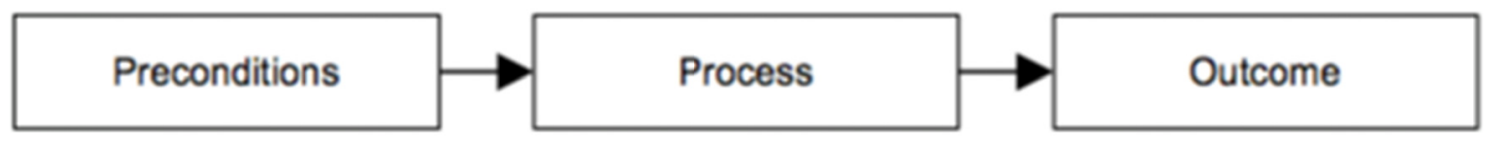

Figure 1. Wood and Gray (1991), three phases of inter-organizational collaboration

\subsection{Initial Theoretical Framework of the Study}

The theoretical framework of the study was initially made up of four theories that the researchers thought would be applicable in investigating challenges in the inter-organizational collaboration process. These theories were the bullshit theory, adaptive communication theory, collective identity theory and swift trust theory. The theories were chosen after extensive review of literature relating to inter-organizational collaboration process. However, these theories were found to be limited and to exclude other relevant challenges that were emerging in the data. The researchers therefore, reviewed several collaboration models and instruments which have been developed in order to assess their suitability for the study. Most of the models reviewed were found to focus on specific disciplines and could be applied to a multi-disciplinary context; which is the nature of this study. Among the models reviewed was the Collaboration and Trust in an Education Context by Tschannen-Moran (2001), which is an instrument that measures collaboration between principals, teachers and parents. Collaboration Index: a measure for supply chain collaboration by (Simatupang \& Sridharan (2005), is a scale that measures collaboration amongst participants involved in supply chains. CoSpaces Collaborative Working Model by Patel et al (2012), is an instrument designed in the aerospace, automotive and construction industries, and it is applicable to a business context. Collaborative Culture Scale by Perez, Peon \& Ordas (2011) is a scale that measures the values attributed to a collaborative culture. Assessment of Inter-professional Team Collaboration Scale by Orchard, King, Khalili \& Bezzina (2012) is an instrument to measure collaboration between teams of health professionals. The study therefore sought a more diverse model that could encompass the wide range of challenges emerging in the empirical data.

\subsection{Thomson and Perry (2006), Model of Collaboration Process}

Thomson (2006) developed a theoretical model of collaboration to fulfill the black box identified by Wood and Grey in their literature review. It was argued by Wood and Gray (1991), that much literature focused on preconditions and outcome and there was absence or inadequate literature on the interactive process of the collaboration. Other authors; Ring and Van De Ven (1994), Thomson and Perry (2006) and Thomson et al. (2007) also supported this view. This gap identified by Wood and Gray (1991) is what they called a black box. In line with this, Thomson and Perry (2006), developed a theoretical model on the process of collaboration from previous research on collaboration, inter-organizational relations and organizational behavior. The theoretical model was developed to fill the black box identified by wood and Grey (1991), by providing insight for an integrative view of collaboration as a process. The model consists of five key dimensions which characterize the nature of collaboration process. Thomson and Perry (2006), argue that these dimensions should provide a guide towards the collaboration process. They further argue that the five variable dimensions; governance, administration, organizational autonomy, mutuality, and norms must be known and managed intentionally in order to collaborate effectively. Since the model gives an outline of how effective collaboration process functions, the researchers investigated the challenges in inter-organizational collaboration using these five dimensions of the process of collaboration. The Thomson and Perry (2006), model was used as the theoretical framework for this study because it fits the context of the study as it focuses on the process of collaboration which is also the 
focus of the study. The model was also selected because is applicable in multiple contexts unlike the other models reviewed. The theoretical model is shown below.
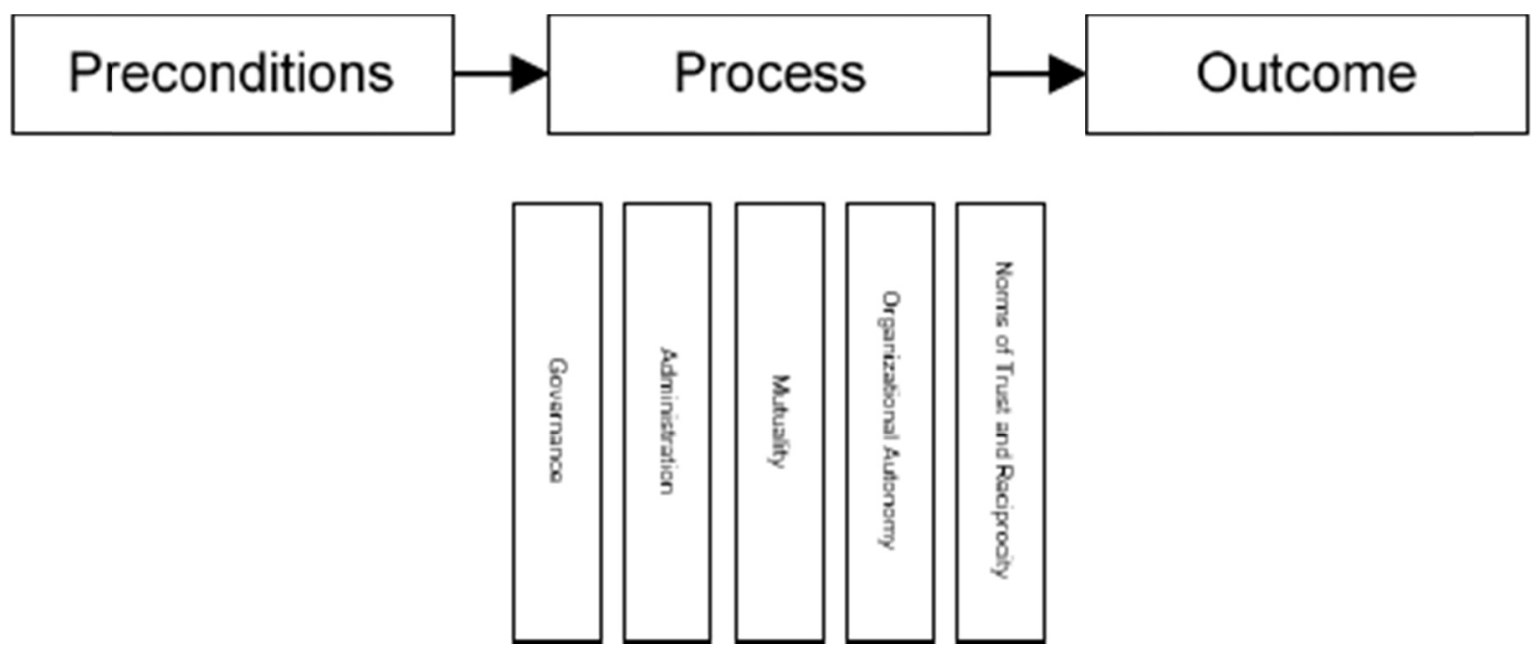

Figure 2. Thomson and Perry (2006), model of collaboration process

The five dimensions of the model are shown below and will be explained further below.

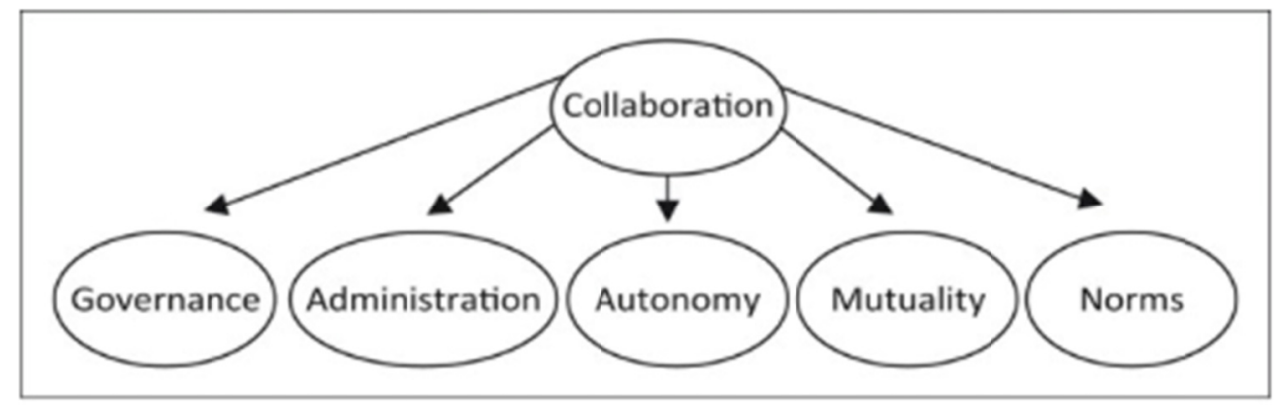

Figure 3. Thomson and Perry (2006), model of collaboration process

\subsubsection{Governance}

According to Thomson and Perry (2006), one aspect of governance is that the leaders of collaborating organizations should support collaboration. This implies that creating and maintaining a collaboration requires leaders to play a critical role (Kaats \& Opheij, 2014; Patel et al., 2012). Additionally, in order for collaborating parties to benefit from the collaboration and to better work together, governance provides the involved parties in the collaboration with structure (Wallin \& Von Krogh, 2010). This includes agreed upon rules of engagement, decision making, required information and flow, distribution of costs and benefits (Ostrom, 1990). Maintaining mutuality, conflicts, functional relationships and order in a collaboration is also an important aspect of governance (Williamson, 2002). Blomqvist et al. (2005), explains that contracts are also the central issue of governance. This is because these bind the involved parties and create obligations (how to act, responsibilities of each party) in form of a formal, written between two or more parties, therefore, enabling cost and risk reduction (Blomqvist et al., 2005). The theory suggests that the varying governance dynamics can make or break collaboration. Hence clear governance strategy helps to reduce anxiety and failure (Kaats \& Opheij, 2014; Wheelan, 2005).

\subsubsection{Administration}

To achieve the purpose that brought the organizations to the table in the first place, some kind of administrative structure must exist that moves from governance to action (Thomson \& Perry, 2006). Administration is hence an important dimension in effective collaboration because collaborations do not administer themselves (Thomson \& Perry, 2006). Some aspects to consider for effective collaboration in relation to administration include planning, clarification of roles, responsibilities, procedures and agreement on administrative responsibilities (Mattessich et 
al., 2001). This is in-line with Thomson and Perry (2006), who also believe that clear roles and responsibilities, the capacity to set boundaries, the presence of concrete achievable goals, and good communication are characteristics of administration. Another aspect of administration is the regular monitoring and feedback between teams to establish achievement of collaborative goals is yet an important aspect in collaboration. This is because monitoring and feedback of the performance of the collaboration is critical for continuous improvement (Frey et al., 2006; Gajda, 2004; Peterson, 1991). There is therefore a need for systems and administrative structures to move from governance to action (Thomson \& Perry, 2006).

\subsubsection{Autonomy}

According to Thomson and Perry (2006), autonomy is defining dimension of collaboration that captures both the potential dynamism and the frustration that is implicit in collaborative endeavors is the reality that partners share a dual identity: They maintain their own distinct identities and organizational authority separate from (though simultaneously with) the collaborative identity. They believe that participants of a collaboration should share a dual identity as this is a descriptive for a collaborative effective endeavor. However, there is always tension between self-interest and collective interest among collaborating organizations (Thomson \& Perry, 2006). The willingness of pursuing collective goals and liability towards the collaborative undertakings of interest to different participants is what characterizes collective interest while maintaining the organization's own distinct identity from the collaborative arrangement and attaining organizational goals is what categorizes organizational self-interest (Wood and Gray, 1991). Another dimension to autonomy in relation to collaboration is power dynamics. Cropper et al. (2009), argue that power is needed by organizations participating in collective activities to influence, access, and impact decisions regarding joint goals and the way they are carried out. Inter-organizational relations work more smoothly and efficient when the power balance is fairly divided, however, equality of power among actors present in a collaboration cannot be expected (Cropper et al., 2009). Power struggle could potentially inhibit its effectiveness for the parties involved in the collaborative endeavor (Cropper et al., 2009).

\subsubsection{Mutuality}

Mutuality defined as values and beliefs about inherent value of collaborating for mutual gains (Campbell, 1997, p.1) is a fundamental aspect in collaboration. Thomson and Perry (2006), state that, although information sharing is necessary for collaboration, it is not sufficient for it to thrive. Mutuality has its roots in interdependence and shared benefits. Powell (1990), supports this view as he states that collaboration must yield mutual benefits, stressing the need for collaborator's interests to be directed towards a shared goal and collective benefits. This is also in line with Thomson and Perry (2006), who explain mutuality in collaboration with respect to gains from the outcome and information sharing causing interdependence. Understanding and mutual respect are therefore important elements in collaboration (Mattessich et al.,2001). In order to maintain an effective collaboration therefore, involved parties need to recognize and respect differences between their organizations (i.e. culture and values) as well as create mutuality (Mattessich et al.,2001). This entails that the collaborating organizations should put the collective interests of collaboration above their individual interests as this is the key success factor for successful collaboration (Hudson et al., 1999; Mattessich et al., 2001; Srivastava \& Banaji, 2011; Tsasis, 2009). The failure to establish mutuality in collaboration may therefore affect the effectiveness of collaboration (Thomson \& Perry, 2006).

\subsubsection{Norms}

Trust and reciprocity are two important norms that are important in collaboration because one party must be willing to trust the other party and believe that it will even out at the end (Thomson et al., 2007). The norms dimension of this theoretical framework, therefore, relates to trust and the need for competence and consistency from representatives of collaborating parties (Adams et al., 2008; Barczak, Lassk \& Mulki, 2010; Johnson \& Grayson, 2005). History is important in collaboration as it provides a foundation for both communication and trust in the collaborative arrangement (Mattessich et al., 2001). Trust is, therefore, an important element in inter-organizational collaboration as it can reduce costly governance mechanisms, act as a substitute for contracts and cause effectiveness in collaboration (Thomson et al., 2007). It may be thought out that creating trust in a collaboration should be very simple, however, this is likely not the reality in practice (Mattessich et al., 2001).

\section{Methods}

\subsection{Selection of Focus Organizations of the Study}

The researchers first contacted region Skåne in order to identify organizations that are collaborating towards the open Skåne 2030 strategy. The researchers were informed that there are many organizations collaborating 
towards the strategy. However, since this nature of collaboration involves constant emerging new collaborations, it is hard to track the number of collaborating entities. Region Skåne, therefore, identified eight collaborating organizations which could be potentially used for the study. The criteria for the selection of these organizations is not known since the selection of these organizations was independent of the researchers and totally done by region Skåne. The researchers then used random sampling methods to select three organizations from the eight, and these were used as a focus of this study. Random sampling was used to select the organizations because it provides an unbiased selection and a representative sample which are important in drawing conclusions from the results of a study (Sharma, 2017). The three selected organizations will be referred to as organization 1, organization 2 and organization 3 for confidentiality purposes and are described below.

Organization 1 is a public-sector organization that works for development where economic growth, environmental and good living conditions go in alignment with open Skane 2030 strategy. So, it aims for a clean-living environment, a stable labor market and a good life for the residents and thus working towards sustainable development in the region. Therefore, the organization's work focuses on different aspects such as regional growth, infrastructure planning, integration, environmental issues, and public health. Organization 2 is also a public-sector organization that is responsible for issues such as infrastructure planning, business development, environmental and planning strategy work and interregional cooperation and public health. Organization 3 is a private sector organization which focuses on providing a professional business guidance across all sectors to researchers, entrepreneurs, innovators or anyone with a great idea to build a strong internationally minded enterprise. It offers guidance to the innovative employees in healthcare in the region of Skane as well as to external business partners, who wish to develop and commercialize new healthcare products.

\subsection{Selection of Participants}

The selection of participants of the study from the three selected organizations was done using a two-fold criterion; first respondents were selected based on their involvement in management and secondly based on them being employees of the organizations under study. Management in the study was defined as being involved in the administration of the collaborations towards the strategy while Employee was defined as having a non-administrative role in the collaboration. This criterion was used in order to generate a multi-perspective picture of the challenges in inter-organizational collaborations process at different levels. The multi-perspective view of the challenges is important in understanding and working with the complex nature of the collaboration towards the open Skåne 2030 strategy (Skane2030.se, 2018).

The researchers used snowball technique to recruit participants of this study. According to Heckathorn (2015), Snowball sampling or Chain-referral-sampling is useful for recruiting hard to identify or hidden participants. It begins with a convenience sample of an initial subject who serves as "seeds," through which wave 1 subject is recruited; wave 1 subject, in turn, recruit wave 2 subjects; and the sample consequently expands wave by wave like a snowball growing in size as it rolls down a hill. In line with this, the target group of this study was hard to identify. So, region Skåne initially gave the researchers names and contacts of individuals at each of the selected organizations. These served as "seeds" as they were asked to recommend other participants from their respective organizations both at management and employee level. This pattern continued until the desired number of participants was obtained.

\subsection{Data Collection}

Data for this study was collected through semi-structured interviews. The interviews were semi-structured in nature because they were based on a fixed number of predetermined questions with room left for follow up questions (Merriam, 2009). The researchers used semi-structured interviews because of the nature of this kind of data collection method allowing the development of additional insight on the topic under study and the building of knowledge through generative dialogue on the research topic (Bishop \& Glynn, 1999). Additionally, due to the complexity of the topic under discussion, semi-structured interviews provided an opportunity for the researchers to explore the research topic in-depth and develop insights that other methods do not facilitate (Wellington, 2000).

The interview guide for this study was based on the theoretical framework which included adaptive communication theory, bullshit theory, swift trust and collective identity theory. Two initial interviews were conducted to test the interview guide. It is important to always test the interview guide in order to get feedback on questions that are not clear, those that are unambiguous and need to be reframed (Mutch, 2013). In line with Mutch (2013), the two initial interviews conducted showed that the challenges in the inter-organizational collaboration process were diverse and of a vast nature. The interview guide was however limited by the theoretical framework as it only focused on specific areas i.e. communication. Due to the abductive nature of the 
study, which calls for constant re-adjustment of the theoretical framework as empirical data is being collected (Merriam, 2009) the researchers then adapted the interview guide to a more diverse theoretical framework (Thomson \& Perry, 2006) used for this study. The interview template is found in appendix 1 while the framework is explained in detail in chapter 2 (Theoretical Framework).

The researchers conducted seven face-to-face and one phone interview according to the convenience of the respondents. The interviews took approximately 1 hour and were conducted by both the researchers. A total of 8 participants from the three focus organizations were interviewed for this study and all interviews were audio-taped. It was important for the researchers to record the interviews so that they can be able to go back and verify facts (Merriam 2009). Below is a table showing participants for this study.

Table 1. Summary list of participants

\begin{tabular}{llllll}
\hline Name & Level & Position & Organization & Mode of interview & Interview date \\
\hline Respondent 1 & Management & Manager of integration development & Organization 1 & Face to face & $01 / 05 / 2018$ \\
Respondent 2 & Employee & Integration developer & Organization 1 & Face to face & $02 / 05 / 2018$ \\
Respondent 3 & Management & Head of the regional employee's ideas & Organization 2 & Phone & $02 / 05 / 2018$ \\
Respondent 4 & Employee & International project manager & Organization 3 & Face to face & $04 / 05 / 2018$ \\
Respondent 5 & Management & Administrator at the regional development strategy & Organization 2 & Face to face & $04 / 05 / 2018$ \\
Respondent 6 & Management & Strategist and manager of sustainability and growth & Organization 2 & Face to face & $07 / 05 / 2018$ \\
Respondent 7 & Employee & Innovation advisor & Organization 3 & Face to face & $07 / 05 / 2018$ \\
Respondent 8 & Employee & Environmental coordinator & Organization 3 & Face to face & $07 / 05 / 2018$ \\
\hline
\end{tabular}

*The respondents and organizations were anonymized for confidentiality sake

* organization 1 (public-sector), organization 2 (public-sector), organization 3 (private-sector)

\subsection{Data Analysis}

After the interviews had been conducted and audio tapped, they were then manually transcribed. Coding is the major method of data analysis in qualitative research and is aimed at deconstructing or fracturing the data and develop patterns, themes, or categories that are grounded in the data (Hill et at., 2005). This is the data analysis technique that was adopted for this study. The first part of the coding process was the open coding which involved no pre-determined codes. There were no specific codes predetermined at the first part of the coding process and thus this part of the process is described as open coding (Bryman and Bell, 2011; Merriam, 2009). This is regardless of the fact that researchers were guided by the framework they used as a structure for the semi-structured interviews. The initial coding process was unstructured and open in order to make it possible for the researchers to be able to capture what respondents referred to and avoid reinforcing them to refer what the researchers wanted them to refer to. As part of the initial coding process, the researchers listened to all the interview and read through the transcripts one after the other in order to identify themes that were mentioned by most respondents. Both the researchers conducted this process separately and repeatedly so as to ensure that all emerging themes were captured. The coding process was said to have reached saturation when no new themes were emerging. The researchers then made a conclusive list of all the challenges that emerged.

The next step of the data analysis was about a second order coding. Bryman and Bell (2011) explained this step as categorizing the codes and the authors become more selective in the approach of categorization. The researchers assigned the emergent themes according to the five dimensions of the Thompson and Perry (2006) model of collaboration. The researchers checked for keywords in each of the dimensions and these were used to guide the assigning of themes to the different dimensions of the model. Themes that could not be categorized in any of the dimensions but deemed as important were added to the researcher's own generated dimensions i.e. political influence.

\subsection{Quality in Research}

This research considered two aspects of quality; validity and reliability. Validity also is known as trustworthiness is mainly concerned with the consistency of interpretations grounded in data (Bryman \& Bell, 2011). The researchers employed triangulation, which involves confirmation of the findings from more than one source of data and method (Bryman \& Bell, 2011) in order to ensure the validity of the research and provide greater 
confidence in the findings. This study considered aspects of reliability as it ensured that the measurement instrument used to tackle the research problem including the design, methods, and process of analysis was relevant and inconsistency with the research purpose.

\subsection{Ethics in Research}

- The researchers upheld the following ethical considerations for this research.

- The researchers requested for consent from the participants before carrying out the study.

- The researchers were honest with the participants, audience, readers \& stakeholders with the findings of the study.

- The researchers upheld confidentiality.

- The researchers avoided plagiarism and acknowledge sources of information used in the study.

- Lastly, the researcher made sure there were no negative effects of participating. The researcher ensured that the study causes no harm.

\section{Presentation of Findings}

With regard to the collaboration process towards the open Skåne 2030 strategy, the study found challenges in all the five dimensions of the Thomson and Perry (2007), the model of collaboration both at management and employee level. In addition to the five dimensions, the study found that political influence was a major challenge and therefore was added to be the sixth dimension in the framework. The findings of the study are presented below.

\subsection{Governance}

When asked about governance challenges, four themes emerged; leadership, structure, nature of collaboration and strategic adaptation. Leadership was a shared challenge at both management and employee level while the others were only seen at management level.

\subsubsection{Leadership}

Both employee and management level respondents expressed leadership as a challenge in the collaboration process. At the management level, different aspects of leadership were identified to cause challenges in collaborations. The respondents explained that there are usually differences in leadership styles in different organizations. The differences in leadership then affect how each organization functions and in-turn affects collaboration. Respondent 5 highlighted this when she explained that, "the lack of leadership skills in one platform can affect the functionality of a collaboration" (Respondent 5, personal communication, May 2, 2018). Another dimension of leadership that the respondents identified was that inadequate leadership usually causing unclear goals and objectives because the leader is not able to communicate these clearly. According to respondent 5, "In some platforms, the objectives and goals are clearer than in others because there are different coordinators and leaders" (Respondent 5, personal communication, May 2, 2018). Further, the knowledge level of leadership was mentioned as a challenge to the collaboration process. Respondent 1 sighted that, "Sometimes, leaders do not have good competence in the collaboration process knowledge and this affects their ability to make the decision that is supposed to be made" (Respondent 1, personal communication, May 1, 2018).

At employee level, respondents cited that leadership contributes to challenges in the inter-organizational collaboration process. One aspect that they highlighted was that leaders are not present at the lower level of the organizations in order for them to be able to know what is happening and capture important ideas that could be useful for the functionality of collaborations. The employee level respondents also further explained that the leadership style affects people's motivation towards engagement and contribution to the collaboration. They also stated that some leaders are in wrong positions because they do not have leadership skills, and this affects how employees cooperate and react to collaboration. Respondent 4 highlighted that "You don't always have the right people in the right place because many people are put in positions where they should not be. If someone has 10 years of experience it does not mean they have the right competence for leadership. It is possible for someone with fewer years (say 5years) to have the right skills, motivation, and innovation but they are not always given a chance. This I think has really affected the functionality of most collaborations"(Respondent 4, personal communication, May 4, 2018). The respondents also mentioned that leadership really affects the effectiveness of collaborations because it influences other factors like employee motivation to participate in collaborations, lack of understanding, unclear goals and responsibilities, poor communication which all bring challenges in collaboration. Respondent 7 explained that "People's commitment to any collaboration is always affected by their perceived importance, clear objectives, and motivation. However, leaders do not always make these clear 
making employees not to contribute fully to collaborations" (Respondent 7, personal communication, May 7, 2018).

\subsubsection{Structure}

The management level respondents explained that the strategy addresses a variety of complex issues and matters making the structure complex. They further explained that the structural complexity creates challenges in identifying and concretizing sub collaborative strategies. Respondent 1 explained that "The collaboration towards the strategy is really complex with different authorities, organizations and government departments and this sometimes creates problems in maintaining collaborations" (Respondent 1, personal communication, May 1, 2018). The respondents also related complexity in structure to a lack of a well-designed collaboration structure based on a logical framework to guide how collaborations should be governed. This was seen to cause challenges in collaboration as there is no norm for the right thing to do and usually left to the collaborators to decide. The challenges in the collaboration process in relation to the structure were also linked to organizational structure. Respondent 3 as he explained that, "each organization has its structure and how things work finding a balance between collaborating is sometimes a challenge"(Respondent 3, personal communication, May 2, 2018). The structure was hence said to cause challenges in collaboration in different ways.

\subsubsection{Strategic Adaptation}

The collaboration process towards implementation of the strategy was also said to be affected by the lack of strategic adaptation. The management level respondents explained that collaborations are made based on the current aims of the strategy, but society is changing bringing about new challenges and opportunities which are not reflected in the strategy. According to respondent 5,"Integration in 2014 when the strategy was formulated was a new challenge but now emerging issues like plastic pollution and environmental protection are now more pressing... but not to say this is no longer important. This affects collaboration functionality because people might want to focus on more pressing issues which have come up since"(Respondent 5, personal communication, May 4, 2018). The lack of strategic adaptation of the strategy to the changing needs of the society was hence reflected as a challenge affecting the collaboration process. Respondent 5 also explained that "Changes in the regions and society at large if not adapted to the strategy makes some collaboration's relevance to be questioned therefore causing challenges...this has been identified and there are currently discussions held in order to update the strategy". Respondent 5 further explained that "The changing societal needs are challenging the process of collaboration to adapt the strategy to meet the changing needs" (Respondent 5, personal communication, May 4, 2018). The lack of strategic adaptation was hence seen to cause challenges in collaboration.

\subsubsection{Nature of Collaboration}

In relation to the nature of collaboration, the management level respondents said that the nature of collaborative platforms (formal or informal) create challenges in the process of collaboration. They explained that some collaborative platforms include representatives from different organizations who share similar interests in a certain topic and thus collaborate on informing, discussing, and updating each other on what is happening in their respective areas at the moment and then conduct implementation plans separately in organizations afterward. But some of the collaborative platforms include collaborators who work together in joint actions and not separately in order to implement actions that go in alignment with the strategy. The former was seen as a problem because collaborating entities normally don't feel obligated to the collaboration as it is usually hard to enforce this nature of collaboration

\subsection{Administration}

Six themes emerged in relation to administrative challenges. Communication, lack of clear objectives and goals, drive for collaboration were shared challenges among both levels while, the unclear division of responsibilities, lack of transparency and institutional memory were seen only at management level.

\subsubsection{Communication}

Both employees and management level respondents highlighted communication as a challenge in the inter-organizational collaboration process. At employee level, communication was expressed as one of the major factors contributing to challenges in collaboration. The respondents expressed that it is a challenge for management to communicate the strategy down to the people on the floor so that they should be able to know what role they play in the collaboration. They explained that organizational structure and leadership affects communication between the top management and employees. Respondents from hierarchical organizations expressed concern that there are always communication problems within the organizations causing information to only be known to management level. Communication problems were said to affect collaboration with respect 
to the fact that it brings about unclear objectives, unclear roles and responsibilities and lack of involvement in the collaboration. According to respondent 4, "there are always communication problems because management is not utilizing communication strategies like social media to explain and communicate the strategy and collaborative goals and objectives to all levels of the organization" (Respondent 4, personal communication, May 4, 2018). The respondents linked poor leadership to communication problems which they further linked to challenges in collaboration.

At the management level, the respondents explained that even though communication worked really well in the initial phases of the strategy, communication was a challenge in the later phases. An example was sighted that some collaborators have the same responsibilities to achieve and it is uncertain to communicate which organization should control which responsibility and this has created challenges in the process of collaboration. Respondent 3 highlighted the communication problems as she explained that, "Some organizational responsibilities are overlapping with each other and thus caused conflicts in communicating certain tasks to the right people" (Respondent 3, personal communication, May 2, 2018). Further, the respondents said the lack of communicating the results of a collaborative action as well as the lack of defining the connection between the results and the strategic goals caused challenges in the collaboration process as it was said by Respondent 5 , "many meetings and fewer actions" (Respondent 5, personal communication, May 4, 2018). Inadequate communication in some collaborations between organizations was also seen to cause challenges in collaboration. Further, the strategy was said to have varying interpretations and to be understood differently even though all organizations collaborating are informed. This was connected to communication problems.

\subsubsection{Lack of Clear Objectives and Goals}

The employee level respondents explained that most collaborations face challenges due to lack of clear objectives. They explained that objectives and goals are usually vague to people down the organizational hierarchy and this makes the employees not to be able to know if their work contributes to the attainment of collaborative endeavors. They further explained that the lack of clear objectives and goals among the employees affects the functionality of collaboration because people do not always commit to things they do not understand. Respondent 2, explained that "I am not sure if my work is contributing to the collaboration, I just do my daily duties as per my job description" (Respondent 2, personal communication, May 2, 2018). It was expressed that most of the objectives and goals of collaboration are known at management level and people at the lower level do not really understand the objectives and this affects the collaboration process. Respondent 8 , stated that "if the objectives are not known, people will not jump along in the vision and participate" (Respondent 8 , personal communication, May 7, 2018).

At the management level, in line with communication, unclear goals and objectives were seen to affect the collaboration process. The lack of clear objectives, goals, and actions in some organizations was seen to cause many challenges in the collaboration process. One challenge was how to motivate and make people work towards implementing the strategy since it might not be clear if what the organizations are focusing on is part of the strategy or not because the strategy is complex with a lot of activities and guidelines. According to respondent 5, "The process of engaging collaborators throughout the implementation process in order to achieve a collaborative decision making is a big challenge because of unclear goals and objectives" (Respondent 5, personal communication, May 4, 2018). In this regard, communication was seen to cause challenges in the collaboration process. Respondent 8 added to this as he explained that "every time we meet, there are new topics and agendas for new issues that $\mathrm{X}$ organization think it is necessary, thus there is no prioritized agenda that includes specific goals that are achievable in a specific timeframe" (Respondent 8, personal communication, May 7, 2018).

\subsubsection{Unclear Division of Responsibilities}

At the management level, related to unclear goals and objectives, the respondents thought dividing responsibilities among collaborators and the actual implementations of the goals that were agreed upon in the strategy were seen as a challenge. The respondents highlighted that, there is no clear division of responsibilities. The collaborations are usually based on requesting different organization to humbly and softly join the strategy and not requesting certain actions in a formal way. Additionally, the respondents also explained that there is a lack of coordination between the organizations collaborating and this causes overlapping responsibilities and unclear division of responsibilities. According to respondent 6, "The challenge is not to know what the other organization is doing, and this causes overlapping responsibilities" (Respondent 6, personal communication, May 7, 2018). There are overlapping tasks and the responsibilities because everyone wants to develop the region and end up doing the same tasks due to the unclear division of responsibilities. The respondents also explained 
that when collaborators are not involved in the process of collaborative action from the initial phase, a waste of resources and work duplications happens. Sometimes it is not possible for a collaborating organization to contribute efficiently due to internal barriers and restrictions. "When collaborators are introduced to a project later in the process, unexpected challenges always accrue" (Respondent 5, personal communication, May 4, 2018). They also explained that a collaborating organization does not know enough about the other organizations in this collaboration which causes time waste and delay actions because of the lack of knowledge on how X organization works and what regulations and restrictions exist.

\subsubsection{Drive for Collaboration}

According to employee level respondents, in the initial phases of collaboration, collaborators are usually committed and contribute fully to collaboration but maintaining the drive for continued collaboration is, however, a challenge that affects the effectiveness of collaboration. The respondents also said that there are many tasks and responsibilities to be carried out by each organization and sometimes it is possible to concentrate more on the individual organizational tasks than on the collaborative goal. Drive for collaboration was said to affect collaboration process in that when collaborators are not driven they are less effective and productive. Maintaining a drive for collaboration was hence sighted as a challenge in collaboration at the employee level.

At management level maintaining the drive for continued engagement and participation in collaboration was also highlighted as a challenge. The respondents stated that in the initial phases of collaboration, collaborators are usually engaged and contribute fully to collaboration but in the long run, the drive for engagement is not the same hence affecting the functionality of the collaborations. Respondent 1 highlighted that "The main challenge is usually to still have the same goal after collaborating for a while and to move your vision further over time as this requires to have energy and insight in what you want to achieve" (Respondent 1, personal communication, May 1, 2018). Maintaining a drive for continuous collaboration was hence seen as a challenge.

\subsubsection{Lack of Transparency}

At the management level, lack of transparency was said to cause challenges regarding trust in the collaboration process. The respondents explained that collaborating organizations sometimes think that there is always a hidden agenda that supports a personal interest in an organization. The lack of transparency was alluded to access to resources and funds which are not openly facilitated and only a few people know how to access them when needed. Respondent 6 explained that, "There is a lack of transparency in communicating personal interests and values to others and this negatively impacts the collaborative trust among collaborators which inhibits productivity of collaboration since resources are not always used to support a prioritized project that contributes to the overall collaboration" (Respondent 6, personal communication, May 7, 2018).

At Employee level, the respondents believe that leaders are not transparent enough in sharing decisions, the logic behind benefits of implementing these decisions and the contribution of an employee's role to the big picture of collaboration. Employee level participants said decisions were made in closed rooms with a narrowly defined set of leaders but in order for all members of an organization to trust their leadership they need to have some visibility into decisions as they are being made, and into the reasons behind those decisions.

\subsubsection{Institutional Memory}

The management level respondents explained that each time someone leaves their job, a chunk of the organization's memory leaves too. This leads to serious consequences and challenges in running long-term projects and prevents learning from previous mistakes. They further explained that some of the institutional knowledge, which is the stored knowledge within an organization, gets translated into policies and procedures but most of it resides in the hands, heads, and hearts of managers and functional experts in collaboration. Over time, most of this institutional knowledge moves away as people relocate or retire. According to respondent 8 , "Many organizations in this collaboration are at risk of losing their memory because workers and leaders switch jobs often, without passing on what they've learned (collaborative amnesia)" (Respondent 8, personal communication, May 7, 2018). Also, they added that when a new manager introduces different agenda that most likely does not build on earlier knowledge or contradicts what was implemented previously, the institutional knowledge is degraded. They further explained that this knowledge is rapidly forgotten when an organization tends to reorganize or emerge with another and thus experience a subsequent reshuffling of key individuals who are experts in the collaborative process.

\subsection{Autonomy}

When it comes to autonomy, conflict of interest emerged at management level. 


\subsubsection{Conflict of Interest}

At the management level, conflict of interest was highlighted as a challenge in relation to autonomy. The respondents explained that there are differences in priorities among collaborators. For example, the strategy prioritizes both economic growth and environmental protection. There is hence conflict between economic growth and sustainable environment affecting collaborations towards implementation of the strategy. According to respondent 1, "There are serious conflicts of interest that are uneasily solved, and they are on the table. For example, some organizations prioritize economic development while others sustainable environment. The conflicts exist even between departments and this causes conflicts in collaboration" (Respondent 1, personal communication, May 1, 2018). Respondent 3 also explained this has she highlighted, "There is always conflicting ideologies which cause the conflict of interest...it goes beyond the strategy to the world in general, in organizations and even among departments. These embedded conflicts of interest make it difficult to push certain agenda in collaboration." (Respondent 3, personal communication, May 2, 2018). It was hence highlighted that some challenges in collaboration are because there is a major conflict of interest between collaborating organizations which bring challenges in collaboration.

\subsection{Mutuality}

Two themes emerged in relation to mutuality; collective identity and unclear benefits. Both were seen at employee and management levels.

\subsubsection{Collective Identity}

Employee level respondents expressed the lack of inclusion in the collaborative process towards the implementation of the 2030 strategy as a challenge. They explained that they do not feel included in the collaboration process because they do not participate in the decision making. Respondent 2 highlighted that "They usually do not include us; the thing is they do not know how it feels to be down here" (Respondent 2, personal communication, May 2, 2018). It was explained that even though there are is always representatives from their organizations during decision making, the representatives do not usually represent the opinions of the employees because their opinions are not usually taken into consideration. As a result of the feeling of lack of inclusion in the decision making, the employee level respondents felt that the decisions made by management are not always the right decisions. According to respondent 2, "sometimes what they prioritize and make collaborations for is not actually what we need to address at that particular moment and this causes challenges" (Respondent 2, personal communication, May 2, 2018). It was said that it is hard for people to participate and be committed to a collaboration when they do not feel included in the process. Lack of involvement was further associated with having unclear goals and objectives among employee level respondents.

According to the management level respondents, the strategy is only communicated at the strategic/managerial level and it is not shared with everyone in the collaboration. According to respondent 5, "The strategy is for people in management and not for everyone because we think if an employee is working for an organization whose values go in alignment with the strategy values then the employee has an indirect contribution and it is not necessary for them to know more about the strategy" (Respondent 5, personal communication, May 4, 2018). It was further highlighted that only the strategic level need to understand what is happening with strategy while other parties can just participate indirectly. However, this was seen to cause a lack of shared perception of the strategy at different levels and this created challenges in achieving collective actions. The management level respondents associated the lack of shared understanding of the strategy among all level employees to the fact that they have different strategies that they focus on and so it is difficult to communicate effectively all the strategies.

\subsubsection{Unclear Benefits}

At employee level, the lack of understanding of the benefits of collaboration among the employees makes them not to know how to contribute towards the collaboration. The employee level respondents explained that they did not understand the importance of certain collaborations and this affected their motivation towards the implementation of these collaborations.

The management level respondents explained that due to lack of collective identity, the benefits of the collaborations towards the implementation of the strategy are not usually clear to all level employees. It was cited by respondent 6 that "the lack of understanding of a shared benefit between collaborators implementing certain actions creates a challenge in the process of collaboration" (Respondent 6, personal communication, May $7,2018)$. The respondents explained that the benefits of collaborating are not usually clear and shared among all level employees and this causes lack of commitment to collaboration among all employees. 


\subsection{Norms}

Organizational values and culture is the only theme that emerged when it comes to norms and was only found at the employee level.

\subsubsection{Organizational Values}

The culture was highlighted as a challenge in the collaboration process. The respondents explained that collaborations towards the implementation of the 2030 strategy are usually affected by differences in culture among organizations, cities or people. Respondent 8 mentioned that "One challenge is usually that different organizations have a different culture, this also applies to the personal culture which may bring challenges in working together" (Respondent 8, personal communication, May 7, 2018). Managing differences in culture were therefore seen as a challenge. Respondent 4, also highlighted this as she explained that, "Culture is always a hindrance because you have a personal culture, organizational culture, and national culture and you don't know which culture to align to in a collaboration" (Respondent 4, personal communication, May 4, 2018). Another dimension of the culture that was mentioned is that it is cultural for people not to speak out when things are going wrong. This was mentioned by respondent 2 who stated that "when things go wrong people just ignore them and do not speak out ... this brings a challenge to collaboration" (Respondent 2, personal communication, May 2, 2018)

\subsection{Political Influence}

The study found that political influence was a major dimension that brought challenges in inter-organizational collaboration towards the implementation of the open Skåne 2030 strategy. Both the management and employee level respondents highlighted that political influence is usually a challenge because collaborating organizations always have to abide by what the politicians want. This may not always be in-line with what needs to be done at that particular moment. The management level respondents felt that political influence was a challenge because politicians want to take more responsibilities in the strategy and want to take over what the organizations are doing. Additionally, they also expressed that even though politicians want to take responsibility they sometimes do not really know what needs to be done. Challenges in inter-organizational collaboration process were, therefore, alluded to political influence in that sometimes the collaborating organizations implement things that are they don't really want to because it came from the politicians. According to respondent 6 , "The politicians sometimes just assign tasks to organizations without really considering if the organizations are right for the job and how that might affect results ... people are also scared to oppose what politicians say for fear of losing jobs" (Respondent 6, personal communication, May 7, 2018). It was explained that the politicians have not really handed power. Even if they state so, there is always a political influence in the implementation of the strategy.

This is in-line with what employee level respondents highlighted, as they explained that even though the government mandated the region to be responsible for their development and to make the strategy, there is still a challenge with balancing the interests of the political sphere with the interest of the region. Respondent 2 expressed this as she said, "politicians usually forget what they agreed upon". The employee level respondents further explained that some collaborations do not work because of different interests at political levels. Respondent 4 shared the same view when she explained that, "Even though the vision was agreed on there is a layer in organizations that are influenced by politics"(Respondent 4, personal communication, May 4, 2018). The respondents also mentioned the change in political power and office as being a challenge in collaboration towards the 2030 strategy. They highlighted that some collaborations exist over a long period of time, and the change in power may affect the effectiveness of the collaboration and attainment of results. Respondent 4 expressed concern as she said, "We do not know who the leader in the next four years will be, if what we are currently collaborating for and implementing will not be an area of priority in the new government then the relevance of our collaboration will be questioned therefore affecting the functionality" (Respondent 4, personal communication, May 4, 2018). Political influence was hence sighted as causing challenges in the inter-organizational collaboration process. 
Table 2. Summary of challenges in inter-organizational collaboration process at management and employee level

\begin{tabular}{lclll}
\hline Dimensions & Management & Employee & \\
\hline Governance & $\bullet$ & Leadership & Leadership \\
& $\bullet$ & Structure & & \\
& $\bullet$ & Nature of collaboration & \\
& $\bullet$ & Strategic adaptation & Communication \\
\hline Administration & $\bullet$ & Communication & Lack of clear objectives and goals \\
& $\bullet$ & Lack of clear objectives and goals & Drive for collaboration \\
& $\bullet$ & Drive for collaboration & \\
\hline Autonomy & $\bullet$ & Unclear division of responsibilities & & \\
\hline Mutuality & $\bullet$ & Lack of transparency & & \\
& $\bullet$ & Institutional memory & Collective identity \\
\hline Norms & $\bullet$ & conflict of interest & Unclear shared benefits \\
\hline Political influence & $\bullet$ & Collective identity & Organizational values and culture \\
\hline & $\bullet$ & Unclear shared benefits & Political influence \\
\hline
\end{tabular}

\section{Discussion}

A wide diversity of themes emerged from each of the dimensions of collaboration in relation to challenges in inter-organizational collaboration. The wide diversity of the results could allude to the different perspectives of respondents i.e. employees and management level. Additionally, there are challenges in both managerial and employees levels in a collaborative process. Some of these challenges are similar at both levels while others are different as shown in the diagram below.

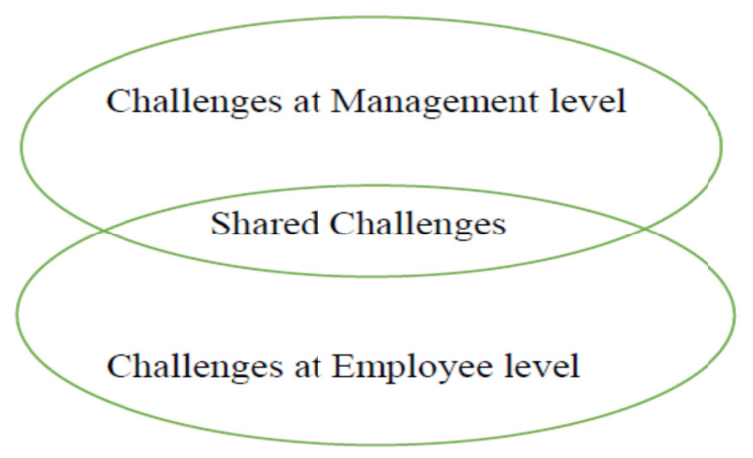

Figure 3. Challenges in inter-organizational collaboration process

However, challenges were found more in management level than in employee level. This was associated with the fact that managers are more involved in collaborative processes of the strategy. For examples nature of collaboration, the structural complexity, and many others.

With regard to the similarities and differences in the challenges, even similar challenges were perceived differently at management and employee levels. For example, even though, leadership was perceived to be a challenge in the governance dimension in both management and employee's levels, the employee's perceived inadequate leadership skills and competencies within their organizations a challenge in collaboration because it leads to a failure in building a collaborative culture and motivating collective intelligence. Resulting in employees not feeling engaged and involved in the entire process and thus, lack of clarity about their contribution to the strategy. This goes in alignment with Amah \& Ahiauzu (2013), who indicate that leadership influences employee involvement and organizational effectiveness. Reversibly, the managers alluded to 
leadership challenges as a result of having different leadership styles within collaborating organizations; some more efficient than others. This is in line with the founder of Cross Current Communication, Sheryl Sever who emphasized the importance of leadership and said that collaboration is a social imperative that needs right people in the bus and in the right seats (Coleman, 2009). The differences in the perception of the challenges at different levels, however, reviewed the complex nature of collaboration and a need to communicate efficiently at all levels of the organization in order to have effective collaboration.

Further, the theoretical framework used for this study, (Thomson and Perry, 2006), presents the five dimensions of collaboration (governance, administration, autonomy, mutuality, norms) as separate entities. However, the challenges in the inter-organizational collaboration process do not exist in isolation for each dimension but there is an inter-linkage between the dimensions. Political influence was also major dimension causing challenges in the collaboration process. The diagram below illustrates the inter-linkage between the dimensions as found in this research.
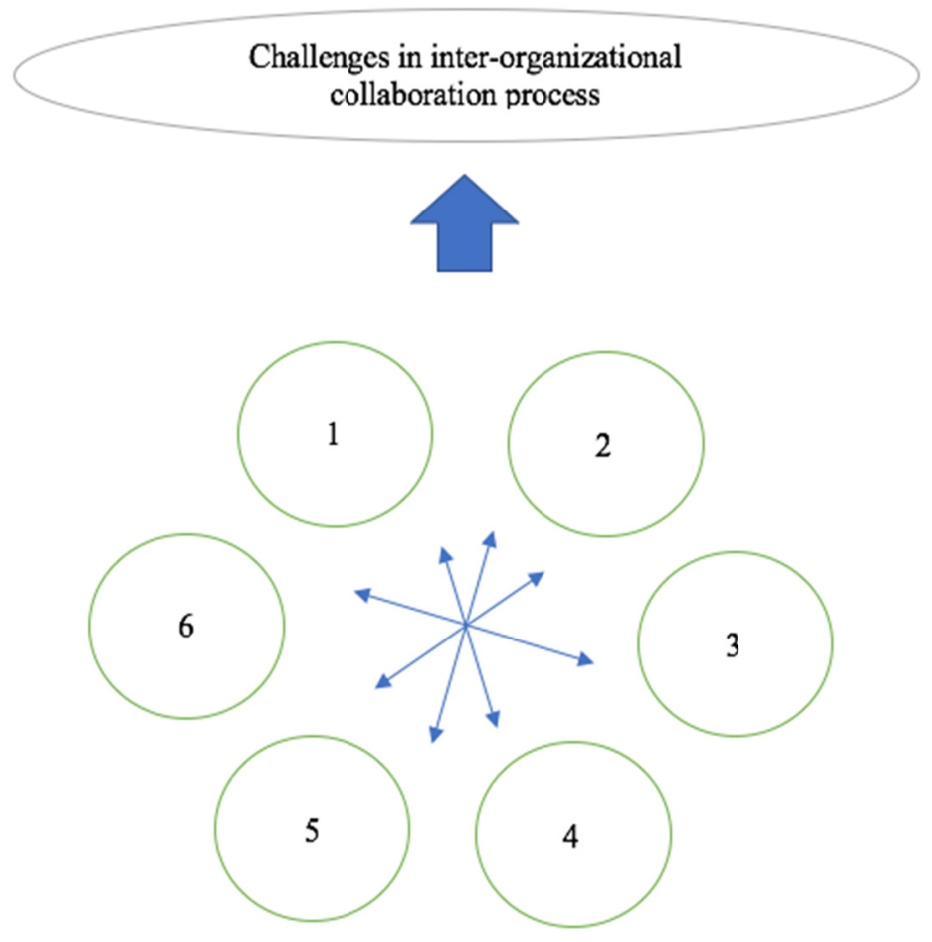

1.Governance 2. Administration 3. Autonomy 4. Mutuality 5. Norms 6. Political influence

Figure 4. Inter-linkage of dimensions model of collaboration process (Adapted from Thomson and Perry (2006) based on the findings of the study)

The inter-linkage between the dimensions shows how challenges in one dimension could affect other dimensions. Inefficient communication as part of the administrative dimension, for example, was linked to several other challenges across different dimensions including lack of clear objectives, lack of clear responsibilities, governance challenges, and collective identity. This is in line with Towler (2003), who also found that communication is the utmost essential key to great leadership, employees motivation, clear goals and achievement of individual, team and organizational goals. One notable example on the effect of communication was that the management level believed that only the strategic level should be involved in the communication of the strategy and did not believe that it was necessary to involve and engage employees as the strategy was complicated to be communicated at each level. On the other hand, the employee level respondents expressed that they felt left out of the strategy and did not really know if their work contributed to the strategy or not due to inadequate communication. This was seen to bring a lack of clear objectives, responsibilities, and lack of collective identity.

Additionally, the inter-linkage between the dimensions was also expressed when the complexity of the activities involved in the regional collaboration was seen to lead to the complex structure and hence difficulties in 
communicating clear sub-strategic goals and objectives which in return affects competent employee's inclusion in collective decision-making processes. A study by (Jacobson, Charters, and Lieberman (2010), supports this as it states that much of the contemporary theorizing about the complex organization is connected with the issues of the ways in which individuals and sub-units can be integrated into the larger structure. Some organizations are more likely to allow the realization of individual and group goals while others limit the opportunity employees have to feel included as part of the structure and make it difficult for them to contribute effectively to the larger group purpose. The complex structure hampers cohesive action and stifles initiative, participation, and innovation. Other authors, Hudson et al. (1999), Kaats \& Opheij (2014), also highlight that structures, processes, and technologies that do not support collaboration can create difficulties.

As highlighted in the model, political influence is a major challenge in collaboration as it influences other dimensions immensely. Political influence was seen to cause challenges in inter-organizational collaboration because the collaborating organizations needed to balance political interests and strategic objectives. Politicians were also said to assign tasks to organizations without considering if it is the right organization for the job or not, making it hard to determine clear objectives and responsibilities, therefore, causing some challenges in governance, administration, and even autonomy. However, the severity of political influence was seen more in public sector organizations as these were said to be in direct link with the government and politicians who had an impact on the collaborative objectives. Yesilkagit and van Thiel (2008) in their study said, "We find that formal autonomy does not reinforce de facto autonomy; organizations with less autonomy report higher levels of political influence when policy autonomy is concerned; and that organizations with more autonomy report higher societal influence on their financial autonomy" and this supports what the empirical data of this study found.

There are also contradicting views emerging from the study. For example, in regard to the nature of collaboration, empirical data shows that the lack of informal relationships fails to hold collaborators committed to a specified goal but on the same time the lack of informal collaborative relationships suppresses creativity and innovation that tackle needs. The informal collaboration was seen to cause challenges while at the same time it was seen as beneficial in the collaborative process. This, however, supports what is published by Donahue (2014), as he stated that a certain minimum of formality seems increasingly imperative while also informal agreements and implicit cultural codes in collaboration maybe important even though they are hard to analyze or recognize. As an inference, this research goes in alignment with previous researchers as it shows the importance of practicing different styles of collaboration, but it also adds that these differences create different norms that affect how each sub-collaborative regime identifies shared effort and responsibilities including performance indicators for collaborative actions and behaviors, formation of shared objectives and establishing agreed to report cineraria in regular basis.

The study also set out to investigate if trust causes challenges in the inter-organizational collaboration process. Regardless, Coleman (2009), said in his book about the successful collaboration that trust is not a significant challenge in a collaborative process and even though the trust is low among collaborators, they can still be productive if they collaborate for an identified and shared objective. In the study's framework, the findings indicate that trust was not really a challenge as collaborating organizations were invited by the region to collaborate towards the strategy because they have the relevant experience and contribution. This coincides with Stuart et al. (2012), who state that trust is affected by the history in collaborative relationships. Even though trust was not directly linked to challenges in the collaboration process, the lack of transparency was linked to causing trust issues.

\section{Conclusion}

In an effort to investigate the challenges in inter-organizational (at employee and management level) using different collaborations towards the implementation of the open Skåne 2030, this study concludes that challenges do exist in all five dimensions of collaboration (governance, administration, autonomy, mutuality, norms) at both management and employee level. Despite this, there are challenges that are only present at one level while others at both employee and management level. In line with the Thompson and Perry theoretical framework, the study added political influence as an important dimension in the collaboration process. Political influence was seen to cause challenges in inter-organizational collaboration because the collaborating organizations needed to balance political interests and strategic objectives. The study also concluded that there is an inter-linkage between the different dimensions of collaboration and proposed a model to show this linkage. Even though political influence was found as a major dimension in this study, it is hard to determine whether this only applies to inter-organizational collaboration towards the implementation of a strategy or that it applies to all kinds of inter-organizational collaboration. We recommend that further research should be done to investigate this aspect. 


\subsection{Theoretical Contribution}

The theoretical contribution of this study includes that, there are challenges in both management and employees level in inter-organizational collaboration. Some challenges are similar while others are different. Further, another contribution is that the five dimensions of the Thompson and Perry (2006) model are not independent as presented in the model but rather influence each other as illustrated earlier in figure 4 . The political influence is an additional contribution of this study as a major dimension in inter-organizational collaboration.

\subsection{Practical Recommendations (Based on the Views of the Respondents)}

1) For collaboration to be successful, trust does help, but understanding the "local context" of a collaborating organization is critical. It is necessary to understand every organization's culture, structure, and regulations because without an understanding of this local context, poor communication occur.

2) It is important to include all of the stakeholders on important decisions that affect them by inviting them early to an opportunity to learn from each other.

3) Collaboration is integral to meeting the goals of each task. Therefore, teams need to facilitate a welcoming environment for new ideas that come from the input of each participant. Each contribution offers unique views of an issue and foster connections between leaders and employees and it also enhances inclusion.

4) Build an Environment of trust. Leaders have to set an example for this behavior through offering open and transparent communication with other team members. It is recommended for them to embrace a communication style that supports free sharing of information between team members.

5) Clear expectations need to be identified at the beginning of every collaborative project or action. This can be implemented by defining "rules of engagement" for collaborators that clearly states the proper ways to interact, as well as what is expected from each collaborator. For example, collaborators can participate in any online discussions about tasks that they are involved in and each team member is expected to respond to direct communications from others within 24 hours. Further, each team member is expected to complete the tasks they have agreed to or let other team members know about a changed situation as early as possible.

6) Begin with small tasks that provide the empowering experience of accomplishment for one collaboration because it is important to knowledge those small achievements to continue collaboration.

7) In order to build a trustful environment in collaboration, pay attention to formality and details while setting expectations by crafting clear agreements and including a process that supports getting back to agreements when conflicts occur. When collaborators have different implicit expectations for a collaboration action, a lot of conflicts occur. Therefore, it is recommended to create a template on a shared workspace and include clear intent and vision, roles and responsibilities, promises that include what each person agrees to do what and by when, the time the agreement will be effective, values that each collaborator contribute in and gets out, structured communication, identify the challenges and fears, shared understating about the necessity to renegotiate when external circumstances happen and every objective cannot be anticipated. Further, include the consequences when promises are broken and the value lost if a collaborative action is not completed for individuals, organization and society. Also, agree on an attitude of resolution and an agreed resolution process when conflicts raise.

8) Team building is highly recommended in the context of regional collaboration. It allows teams to know each member's role; what expertise, experience, and work style each brings; and each other's work context such as other work assignments or extraordinary external and political pressures.

9) Make sure that a common understanding on how collaboration applies to each member's contribution to the big scope is achieved. This will speed up the results of collective work and identity. Also, the accuracy of a collaborative action accuracy will increase.

10) Create a community of focus to motivate people so they know what to collaborate about by creating baseline of documents, blogs, and determine at least two objectives that go in alignment with the community main objectives. Also make it easy and possible for people to find and add content by establishing a proper information design and create a dynamic place where collaborators can find needed information and are empowered to create their own communities that focuses on new areas of interests. But always keep the interests in line with original objectives and reward experts for their knowledge and commitment. Further, promote this community through existing communication channels.

11) Identify and resource people who are responsible for developing a collaborative culture and can identify collaboration opportunities and can build a process of collaboration in a systematic way. 
12) Create an introductory program that can be used as a tool to help new people who enter a collaborative platform in the context of regional development, adapt collaboration practices smoothly.

13) Leadership should focus on fostering and facilitating a constraint-free environment to encourage productive interactions and achieve the identified objectives.

14) It is recommended for politicians in the region to have a helicopter view of the current collaboration practice. There are several collaboration platforms practices towards the regional developmental strategy. Each platform includes several organizations who collaborate for shared objectives that belong to that specific platform which works on one aspect of the overall strategic goals. There is a steering group who represents each platform and act as facilitator and moderators between a collaboration platform and politicians. These people at steering groups should play a significant role in communicating the progress of the strategy and motivate politicians to have conferences or equivalent to be updated on the progress of the current actions towards the regional strategy. Also, to be aware of each platform goals, resources, status reports, budgets, etc.-in a timely manner. An effective communication plan should be structured to help politicians support the strategy properly and avoid and facilitate rules and regulations based on facts rather than assumptions.

\section{References}

Adams, B. D., Waldherr, S., \& Sartori, J. (2008). Trust in team's scale trust in leader's scale manual for administration and analyses. Toronto, ON: HumanSystems Inc.

Amah, E., \& Ahiauzu, A. (2013). Employee involvement and organizational effectiveness. Journal of Management Development, 32(7), 661-674. https://doi.org/10.1108/JMD-09-2010-0064

Andrew, P. S., Pedersen, P. M., \& McEvoy, C. D. (2011). Research Methods and Designs in Sport Management. Human Kinetics.

Barczak, G., Lassk, F., \& Mulki, J. (2010). Antecedents of team creativity: An examination of team emotional intelligence, team trust and collaborative culture. Creativity and Innovation Management, 19(4), 332-345. https://doi.org/10.1111/j.1467-8691.2010.00574.x

Bernard, H. R. (2011). Research Methods in Anthropology (5th ed.). AltaMira Press, p.7.

Bishop, R., \& Glynn, T. (1999). Culture counts: changing power relations in education. Palmerston North: Dunmore Press.

Blaikie, N. (2003). Analyzing Quantitative Data from Description to Explanation. SAGE Publications, London. https://doi.org/10.4135/9781849208604

Blomqvist, K., Hurmelinna, P., \& Seppänen, R. (2005). Playing the collaboration game right-balancing trust and contracting. Technovation, 25(5), 497-504. https://doi.org/10.1016/j.technovation.2004.09.001

Campbell, A. J. (1997). What Affects Expectations of Mutuality in Business Relationships? Journal of Marketing Theory and Practice, 5(4), 1-11. https://doi.org/10.1080/10696679.1997.11501775

Carson, D., Gilmore, A., Perry, C., \& Gronhaug, K. (2001). Qualitative Marketing Research. London: Sage. https://doi.org/10.4135/9781849209625

Chrislip, D. D., \& Larson, C. E. (1994). Collaborative leadership. San Francisco, CA: Jossey-Bass.

Costa, A. C. (2003). Work team trust and effectiveness. Personnel Review, 32(5), 605-622. https://doi.org/10.1108/00483480310488360

Cropper, S., Ebers, M., Huxham, C., \& Smith Ring, P. (2009). The Oxford handbook of inter-organizational relations. New York: Oxford University Press.

Crosby, B. C., \& Bryson, J. (2005). A leadership framework for cross-sector collaboration. Public Management Review, 7(2), 177-201. https://doi.org/10.1080/14719030500090519

Crosby, B., \& Bryson, J. (2010). Integrative leadership and the creation and maintenance of cross-sector collaborations. The Leadership Quarterly, 21, 211-230. https://doi.org/10.1016/j.leaqua.2010.01.003

Dyer, J. H., \& Chu, W. (2011) The determinants of trust in supplier-automaker relationships in the US, Japan, and Korea. Journal of International Business Studies, 42(1), 10-27. https://doi.org/10.1057/jibs.2010.34

Frey, B. B., Lohmeier, J. H., Lee, S. W., \& Tollefson, N. (2006). Measuring collaboration among grant partners. American Journal of Evaluation, 27(3), 383-392. https://doi.org/10.1177/1098214006290356

Gajda, R. (2004). Utilizing collaboration theory to evaluate strategic alliances. American Journal of Evaluation, 
25(1), 65-77. https://doi.org/10.1177/109821400402500105

Gray, B. (1989). Collaborating. San Francisco, CA: Jossey-Bass.

Gray, B., \& Hay, T. M. (1986). Political Limits to Interorganizational Consensus and Change. Journal of Applied Behavioral Science, 22, 95-112. https://doi.org/10.1177/002188638602200204

Greer, P. A. (2017). Elements of Effective Interorganizational Collaboration: A Mixed Methods Study. Dissertations \& theses. 371. Retrieved from http://aura.antioch.edu/etds/371

Grice, H. P. (1975). Logic of conversation. In D. Davidson, \& G. Harman (Eds.), The Logic of Grammar. Dickenson.

Heckathorn, D. (2015). Snowball Versus Respondent-Driven Sampling. Sociol Methodol, 41(1), 352-366.

Heppner, P. P., Kivlighan, D. M., \& Wampold, B. E. (1999). Research design in counseling (2nd ed.). Belmont, CA: Wadsworth.

Hill, C. E. et al. (2005). Consensual qualitative research: An update. Journal of Counseling Psychology, 52, 196-205. https://doi.org/10.1037/0022-0167.52.2.196

Hudson, L., \& Ozanne, J. (1988). Alternative Ways of Seeking Knowledge in Consumer Research. Journal of Consumer Research, 14(4), 508-521. https://doi.org/10.1086/209132

Huxham, C. (1996). Creating collaborative advantage. London, Thousand Oaks: Sage Publications.

Huxham, C., \& Vangen, S. (2005). Managing to collaborate. New York, NY: Routledge.

Jacobson, E., Charters, W., \& Lieberman, S. (2010). The Use of the Role Concept in the Study of Complex Organizations. Journal of Social Issues, 7(3), 18-27. https://doi.org/10.1111/j.1540-4560.1951.tb02237.x

Johnson, D., \& Grayson, K. (2005). Cognitive and affective trust in service relationships. Journal of Business Research, 58(4), 500-507. https://doi.org/10.1016/S0148-2963(03)00140-1

Kaats, E., \& Opheij, W. (2014). Creating conditions for promising collaboration: alliances, networks, chains, strategic partnerships. Heidelberg: Springer-Verlag. https://doi.org/10.1007/978-3-642-41443-5

Kabat-Zinn, J. (1991). Full Catastrophe Living. New York: Bantam.

Kerka, S. (1997). Developing collaborative partnerships. Ohio: ERIC Clearinghouse on Adult, Career, and Vocational Education, Center on Education and Training for Employment, College of Education, the Ohio State University.

Kothari, C. R. (2004). Research methodology: methods \& techniques (2nd ed.). [e-book], New Delhi: New Age International (P) Ltd., Publishers.

Mangoyana, R. B., \& Collits, P. (2014). Collaboration for regional development: A case study of Wide Bay Burnett. Australasian Journal of Regional Studies, 20(3), 430-451.

Mattessich, P., Murray-Close, M., \& Monsey, B. (2001). Collaboration: What makes it work (2nd ed.). Nashville, TN: Fieldstone Alliance.

McCracken, G. (1988). The long interview: Quantitative research methods (Vol. 13). New Delhi, India: Sage. https://doi.org/10.4135/9781412986229

Merriam, S. B. (2014). Qualitative research: a guide to design and implementation, Rev. and expand. (3rd ed.). [e-book], San Francisco: Jossey-Bass.

Meyerson, D., Weick, K. E., \& Kramer, R. M. (1996). Swift trust and temporary groups. In Thousand Oaks, CA: Sage.

Morrow, S. L. (2005). Quality and trustworthiness in qualitative research in counseling psychology. Journal of Counseling Psychology, 52, 250-260. https://doi.org/10.1037/0022-0167.52.2.250

Moulaert, F., MacCallum, D., Mehmood, A., \& Hamdouch, A. (2013). General introduction: the return of social innovation as a scientific concept and a social practice. Collective action, social learning and transdisciplinary research. Edward Elgar, Cheltenham, pp.1-8.

Mutch, C. (2013). Doing educational research; A practitioner's guide to getting stared (2nd ed). Wellington; NZCER Press.

Neuman, L. W. (2000). Social Research Methods: Qualitative and Quantitative Approaches (4th ed.). USA: Allyn and Bacon. 
Orchard, C. A., King, G. A., Khalili, H., \& Bezzina, M. B. (2012). Assessment of inter-professional team collaboration scale (AITCS): Development and testing. Journal of Continuing Education in the Health Professions, 32(1), 58-67. https://doi.org/10.1002/chp.21123

Patel, H., Pettitt, M., \& Wilson, J. R. (2012). Factors of collaborative working: A framework for a collaboration model. Applied Ergonomics, 43(1), 1-26. https://doi.org/10.1016/j.apergo.2011.04.009

Peterson, N. L. (1991). Interagency collaboration under part H: The key to comprehensive, multidisciplinary, coordinated infant/toddler intervention services. Journal of Early Intervention, 15(1), 89-105. https://doi.org/10.1177/105381519101500111

Phillips, N., Lawrence, T. B., \& Hardy, C. (2000). Inter-Organizational Collaboration and the Dynamics of Institutional Fields. Journal of Management Studies, 37(1), 23-43. https://doi.org/10.1111/1467-6486.00171

Powell, W. W. (1990). Neither market nor hierarchy: Network forms of organization. Research in organizational behaviour, 12, 295-336.

Ring, P. S., \& Van de Ven, A. H. (1994). Developmental Processes of Cooperative Interorganizational Relationships. The Academy of Management Review, 19, 90-118. https://doi.org/10.5465/amr.1994.9410122009

Robert, D., Van Wyk, R., \& Dhanpat, N. (2017). Validation of the Thomson, Perry and Miller (2007) Collaboration Instrument in the South African context. SA Journal of Human Resource Management. https://doi.org/10.4102/sajhrm.v15i0.793

Roschelle, J., \& Teasley, S. (1995). The construction of shared knowledge in collaborative problem solving. In C. E. O'Malley (Ed.), Computer Supported Collaborative Learning (pp. 69-97). Springer-Verlag, Heidelberg. https://doi.org/10.1007/978-3-642-85098-1_5

Saunders, M., Lewis, P., \& Thornhill, A. (2012). Research Methods for Business Students (6th ed.). Pearson Education Limited.

Sharma, G. (2007). Pros and cons of different sampling techniques. International Journal of Applied Research, $3(7), 749-752$.

Silverman, D. (2009). Doing Qualitative Research (3rd ed.). Newbury Park, London: SAGE Publications Ltd.

Simatupang, T. M., \& Sridharan, R. (2005). The collaboration index: A measure for supply chain collaboration. International Journal of Physical Distribution \& Logistics Management, 35(1), 44-62. https://doi.org/10.1108/09600030510

Skane2030.se. (2018). Regional Development Strategy, Open Skåne 2030. Retrieved May 22, 2018, from https://www.skane.se/organisation-politik/om-region-skane/Vart-utvecklingsuppdrag/regional-utvecklingsstr ategi-det-oppna-skane-2030/

Srivastava, S. B., \& Banaji, M. R. (2011). Culture, cognition, and collaborative networks in organizations. American Sociological Review, 76(2), 207-233. https://doi.org/10.1177/0003122411399390

Stuart, F. I., Verville, J., \& Taskin, N. (2012) Trust in buyer-supplier relationships. Journal of Enterprise Information Management, 25(4), 392.

Stümer, S., Simon, B., \& Loewy, M. I. (2008). Intra-organizational respect and organizational perspective: The mediating role of collective identity. Group Processes Intergroup Relations, 11(5), 5-20. https://doi.org/10.1177/1368430207084842

Thomson, A. M., \& Perry, J. L. (2006) Collaboration Processes: Inside the Black Box. Public Administration Review, 66(1), 20-32. https://doi.org/10.1111/j.1540-6210.2006.00663.x

Thomson, A. M., Perry, J., \& Miller, T. (2007). Conceptualizing and measuring collaboration. Journal of Public Administration Research and Theory, 19(1), 23-56. https://doi.org/10.1093/jopart/mum036

Thomson, A. M., Perry, J., \& Miller, T. (2008). Linking collaboration processes and outcomes foundations for advancing empirical theory. In R. O'Leary, \& L. Bingham (Eds.), Collaborative public management: The big questions (pp. 97-120). New York: Sharpe.

Torres-Rahman, Z., Baxter G., \& Rivera, A. (2015). Business and the United Nations. Working Together Towards the Sustainable Development Goals: A Framework for Action. SDG Fund, Harvard Kennedy School CSR Initiative and Inspiris Ltd.

Towler, A. (2003). Effects of Charismatic Influence Training on Attitudes, Behaviour, and Performance. 
Personnel Psychology, 56(2), 363-381. https://doi.org/10.1111/j.1744-6570.2003.tb00154.x

Tsasis, P. (2009). The social processes of interorganizational collaboration and conflict in nonprofit organizations. Nonprofit Management and Leadership, 20(1), 5-21. https://doi.org/10.1002/nml.238

Tschannen-Moran, M. (2001). Collaboration and the need for trust. Journal of Educational Administration, 39(4), 308-331. https://doi.org/10.1108/EUM0000000005493

United Nations Sustainable Development. (2018). Sustainable Development Knowledge Development. Retrieved May 23, 2018, from https://sustainabledevelopment.un.org/hlpf/2018/documentation

Wallin, M. W., \& Von Krogh, G. (2010). Organizing for open innovation: Focus on the integration of knowledge. Organizational Dynamics, 39(2), 145-154. https://doi.org/10.1016/j.orgdyn.2010.01.010

Wellington, J. (2000). Educational research: Contemporary issues and practical approaches. London: Continuum.

Williamson, O. E. (2002). The Theory of the Firm as Governance Structure: From Choice to Contract. The Journal of Economic Perspectives, 16(3), 171-195. https://doi.org/10.1257/089533002760278776

Wood, D. J., \& Gray, B. (1991). Collaborative alliances: Moving from practice to theory. Journal of Applied Behavioural Science, 27(2), 3-22.

Yesilkagit, K., \& van Thiel, S. (2008). Political Influence and Bureaucratic Autonomy. Public Organization Review, 8(2), 137-153. https://doi.org/10.1007/s11115-008-0054-7

\section{Appendix 1}

\section{Sample of interview protocol}

\section{Rapport development}

- Presentation of the authors and the thesis

- Purpose of the study

- How the information will be used

- Underline that the respondents are anonymous

- Permission to record interview

- Ask about timeframe for the interview

\section{Background of respondent}

- Could you tell me a bit about yourself?

- What is your current position in this organization?

\section{Five dimensions of collaboration}

Governance

- Can you describe how a collaboration is controlled (contract or informal collaboration)?

- Are there challenges to this form of collaboration?

- How is the collaboration governed?

\section{Administration}

- How is a collaboration handled from an administrative point of view?

- How is decision making handled in your collaboration?

- Is there a shared planning that accrues between you and other collaborators?

- To which extent there is a shared responsibility between you and other collaborators? 
- What are some of the challenges in administration?

- How do these administrative challenges affect the collaboration process?

- Can you describe how you communicate with your collaborators?

- Are there any challenges in communication?

Mutuality

- What is your organizational structure?

- Do your collaborators have the same structure as you?

- If not, how do differences in structure affect collaboration?

Collective identity

- Do you know about collaborative partnership of your organization?

- Do you share the values and norms of this collaboration?

- What is your involvement in this collaborative partnership?

- What are the strategies used to ensure involvement and participation?

- To which extent is there shared responsibility between you and other collaborators?

- Also, how do you perceive this collaboration. (is it a real collaboration)?

- Have you ever perceived this collaboration negatively and tried to investigate more about it in order to improve the situation and or take actions?

Norms

- Do you experience any trust issues in the collaboration process?

- How does this affect collaboration?

General issues and challenges

- Are there any other issues or challenges in the process of collaboration apart from the ones mentioned earlier

\section{Closing}

Do you have any last comments or questions?

Ask for permission to ask clarifying and follow-up questions via e-mail

\section{Copyrights}

Copyright for this article is retained by the author(s), with first publication rights granted to the journal.

This is an open-access article distributed under the terms and conditions of the Creative Commons Attribution license (http://creativecommons.org/licenses/by/4.0/). 